\title{
Prevalence and Metabolic Factors of Hyperuricemia in an Elderly Agricultural and Fishing Population in Taiwan
}

\author{
Qian YU, ${ }^{1,2} \mathrm{Hsi}$-che SHEN, ${ }^{3,4}$ Yi-chun HU, ${ }^{4}$ Yu-fen CHEN, ${ }^{5}$ Tao-hsin TUNG ${ }^{6,7}$ \\ ${ }^{1}$ Department of Foot Science, Fu-Jen Catholic University, New Taipei City, Taiwan \\ ${ }^{2}$ Department of Pharmacy, School of Biomedicine Sciences, Huaqiao University, Quanzhou, China \\ ${ }^{3}$ Department of Healthcare Management, Yuanpei University, Hsinchu, Taiwan \\ ${ }^{4}$ Department of Nursing, Taipei Medical University, Taipei, Taiwan \\ ${ }^{5}$ Institute of Health and Welfare Policy, National Yang-Ming University, Taipei, Taiwan \\ ${ }^{6}$ Department of Medical Research and Education,Cheng-hsin General Hospital, Taipei, Taiwan \\ ${ }^{7}$ Department of Public Health, School of Medicine, Fu-Jen Catholic University, New Taipei City, Taiwan
}

\begin{abstract}
Objectives: This study aims to explore the potential condition-related sex differences to understand the overall pathogenesis of hyperuricemia among the elderly agricultural and fishing population in Taipei, Taiwan.

Patients and methods: This study included 4,372 healthy elderly agricultural and fishing professionals (2,766 males, 1,606 females; mean age $74.4 \pm 6.6$ years; range 65.0 to 90.3 years) voluntarily admitted to a teaching hospital in Taipei, Taiwan for physical exams in 2010 . Their fasting blood samples were drawn through venipuncture, and they were administered a structured questionnaire by clinical nurses.

Results: The overall prevalence of hyperuricemia was $30.4 \%$, which increased significantly with increasing age ( $p<0.001$ ). The prevalence was similar in males (30.2\%) and females (30.6\%) ( $p=0.78)$. Age, obesity, type 2 diabetes, hypercholesterolemia, hypertriglyceridemia as well as low high-density lipoprotein and high blood urea nitrogen, creatinine, and alanine amino transferase levels were significantly associated with hyperuricemia. Hypercholesterolemia (odds ratio $[\mathrm{OR}]=1.26,95 \%$ confidence interval $[\mathrm{Cl}]$ : 1.05-2.50) and high creatinine levels (OR=3.75, 95\% $\mathrm{Cl}$ : $2.64-5.33)$ were significantly associated with hyperuricemia in males, whereas type 2 diabetes (OR=1.54, 95\% Cl: $1.22-1.93)$ and high alanine amino transferase levels $(\mathrm{OR}=1.79,95 \% \mathrm{Cl}: 1.31-2.43)$ were significantly associated with hyperuricemia in females. Hyperuricemia disparity among age groups was also revealed.

Conclusion: Several sex-related differences with regard to factors including age, obesity, type 2 diabetes, hypercholesterolemia, hypertriglyceridemia, low high-density lipoprotein, high blood urea nitrogen, creatinine, and alanine amino transferase levels were indicated in the prevalence of hyperuricemia in this specific elderly population.

Keywords: Agricultural and fishing population; elderly; hyperuricemia; prevalence; sex difference.
\end{abstract}

Uric acid acts as an antioxidant in endothelial cells and maintains vascular dilatation during oxidative stress. ${ }^{1}$ Recent data have shown that hyperuricemia prevalence is increasing worldwide. ${ }^{2}$ This increase is especially pronounced in developed countries, and the additional benefits of therapeutic intervention for hyperuricemia have recently been indicated. Inefficient excretion by the kidneys associated with the overproduction of urate accounts for $<10 \%$ of hyperuricemia cases in the general population. By contrast, inefficient excretion of uric acid, accounting for $>90 \%$ of the cases, results from renal insufficiency or medications that impair renal urate clearance. ${ }^{3}$ At least two-thirds of patients with hyperuricemia may remain asymptomatic, and current evidence does not support treating asymptomatic hyperuricemia. ${ }^{4}$ 
Because hyperuricemia is a critical health problem, the Wilson criteria are used for its routine screening. This requires a thorough understanding of the course of the disease, because patients may present with either a recognizable latent or early symptomatic stage. The clinical tests used for screening are easy to perform and interpret, and are reliable, accurate, acceptable, sensitive, and specific. After screening, an accepted treatment should be started in the event of positive results. From the viewpoint of preventive medicine, regional awareness of the background morbidity of hyperuricemia as well as exploration of the complete spectrum of demographic and biological markers likely associated with hyperuricemia are essential. Sex differences in the prevalence of and risk factors associated with hyperuricemia among specific elderly occupational populations require clarification. Thus, in this study, we aimed to explore the potential condition-related sex differences to understand the overall pathogenesis of hyperuricemia among the elderly agricultural and fishing population in Taipei, Taiwan.

\section{PATIENTS AND METHODS}

This population-based cross-sectional study included a total of 4,372 healthy elderly agricultural and fishing professionals (2,766 males, 1,606 females; mean age $74.4 \pm 6.6$ years; range 65.0 to 90.3 years) voluntarily admitted to New Taipei City Hospital in Taipei, Northern Taiwan for an annual physical exam between January and December 2010.

Complete details regarding the study design and execution have been described elsewhere. ${ }^{5}$ Fasting blood samples were drawn from participants through venipuncture by welltrained clinical nurses. Overnight-fasting serum and plasma samples were frozen $\left(-20{ }^{\circ} \mathrm{C}\right)$ until analysis. Face-to-face interviews along with a structured questionnaire were administered by the nurses during each visit.

Hyperuricemia was diagnosed when serum uric acid levels were $\geq 7 \mathrm{mg} / \mathrm{dL}$ for males or $\geq 6 \mathrm{mg} / \mathrm{dL}$ for females ${ }^{6,7}$ In addition, participants with $\geq 40 \mathrm{U} / \mathrm{L}$ serum alanine amino transferase (ALT) were classified as those with elevated ALT levels. ${ }^{5}$ The definitions of type 2 diabetes and hypertension were based on 1999 World Health
Organization criteria and the Seventh Report of the Joint National Committee on Prevention, Detection, Evaluation, and Treatment of High Blood Pressure, respectively. ${ }^{8,9}$ Participants with a history of type 2 diabetes or hypertension and regularly receiving medication were classified as known cases. The following clinical conditions were used for defining obesity: high body mass index $\left(\geq 25 \mathrm{~kg} / \mathrm{m}^{2}\right)$, hypercholesterolemia (total cholesterol $\geq 200 \mathrm{mg} / \mathrm{dL}$ ), hypertriglyceridemia (triglycerides $\geq 200 \mathrm{mg} / \mathrm{dL}$ ), low high-density lipoprotein (HDL) $<35 \mathrm{mg} / \mathrm{dL}$, high blood urea nitrogen $(B U N) \geq 20 \mathrm{mg} / \mathrm{dL}$, and high creatinine levels $(\geq 1.4 \mathrm{mg} / \mathrm{dL}){ }^{5}$ The study protocol was approved by the Fu-Jen Catholic University Ethics Committee. A written informed consent was obtained from each patient. The study was conducted in accordance with the principles of the Declaration of Helsinki.

\section{Statistical analysis}

Statistical analysis was performed using SAS (Statistical Analysis System) for Windows version 9.2 (SAS Institute Inc., Cary, NC, USA). A two-sample independent $t$ test was used to assess differences in the mean values of continuous variables. Crude and sex- and age-adjusted odds ratios (ORs) and 95\% confidence intervals (CIs) were estimated. Multiple logistic regression analysis was used to evaluate the independence of hyperuricemiarelated factors. A $p$ value of $<0.05$ was considered statistically significant.

\section{RESULTS}

In this study, the overall prevalence of hyperuricemia in the screened population was $30.4 \%$, which significantly increased with increasing participant age according to the chi-square trend test results $(p<0.0001)$. The prevalence of hyperuricemia in males was not significantly higher than that in females (30.2\% versus $30.6 \% ; p=0.78$, Chi-square test). Data were stratified into four broad age groups; females exhibited a higher prevalence of hyperuricemia than males in all age groups, with the exception of the 65-74-year-old group. The age-specific prevalence of hyperuricemia displayed a significant positive association with age according to the Chi-square trend test results for males $(p=0.015)$ and females $(p=0.008)$ (Table 1). 


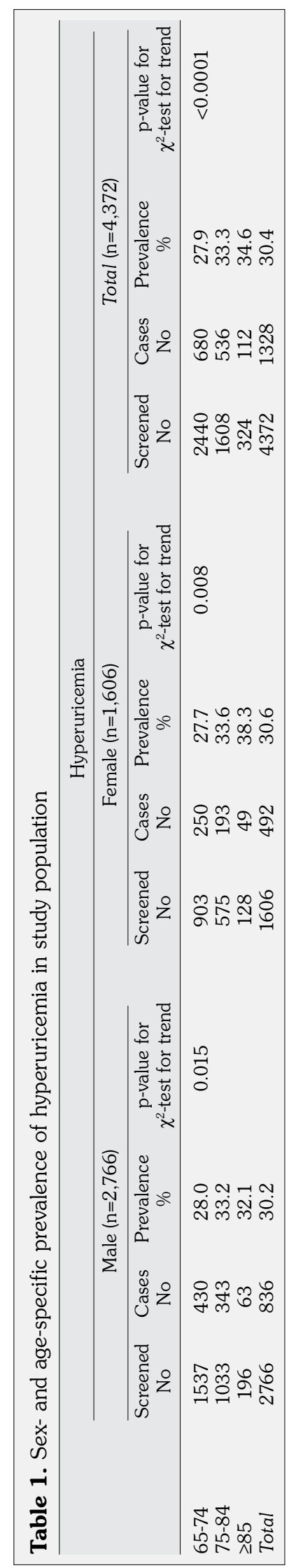

The results of the comparison of various test characteristics and their potential association with specific (serum uric acid) class values (either hyperuricemia or normal) for participants aged $\geq 65$ years are listed in Table 2 . According to the results of the two-sample independent t test, the associated factors significantly associated with hyperuricemia included age (yes, $75.1 \pm 6.7$ years, versus no, $73.0 \pm 6.5$ years), body mass index (yes, $28.0 \pm 6.9 \mathrm{~kg} / \mathrm{m}^{2}$, versus no, $25.9 \pm 5.3 \mathrm{~kg} / \mathrm{m}^{2}$ ), fasting plasma glucose (yes, $102.7 \pm 28.6 \mathrm{mg} / \mathrm{dL}$, versus no, $\quad 99.5 \pm 27.3 \mathrm{mg} / \mathrm{dL}$ ), triglyceride (yes, $153.1 \pm 92.7 \mathrm{mg} / \mathrm{dL}$, versus no, $121.8 \pm 80.6 \mathrm{mg} / \mathrm{dL}$ ), HDL (yes, $50.8 \pm 14.3 \mathrm{mg} / \mathrm{dL}$, versus no, $55.8 \pm 15.1 \mathrm{mg} / \mathrm{dL}$ ), BUN (yes, $19.2 \pm 7.1 \mathrm{mg} / \mathrm{dL}$, versus no, $17.1 \pm 4.7$ $\mathrm{mg} / \mathrm{dL}$ ), creatinine (yes, $1.1 \pm 0.6 \mathrm{mg} / \mathrm{dL}$, versus no, $0.9 \pm 0.3 \mathrm{mg} / \mathrm{dL}$ ), and ALT (yes, $33.2 \pm 26.1 \mathrm{U} / \mathrm{L}$, versus no, $30.6 \pm 21.1 \mathrm{U} / \mathrm{L}$ ) levels. In addition, to examine whether sexrelated differences in hyperuricemia are related to differences in clinical parameters, Table 2 also shows that triglyceride, BUN, creatinine, and ALT levels were significant factors associated with hyperuricemia in both males and females.

The crude and age- and sex-adjusted ORs for the association between relevant risk factors and hyperuricemia are presented in Table 3. Compared with individuals who exhibited normal uric acid levels, those with hyperuricemia revealed a more pronounced prevalence of obesity (adjusted OR=1.53, 95\% CI: 1.32-1.77), type 2 diabetes (adjusted OR=1.16, 95\% CI: 1.01-1.33), hypercholesterolemia (adjusted OR=1.22, 95\% CI: 1.06-1.41), hypertriglyceridemia (adjusted $\mathrm{OR}=1.78$, 95\% CI: 1.52-2.09), low HDL (adjusted $\mathrm{OR}=1.54,95 \% \mathrm{CI}: 1.28-1.86$ ), high BUN (adjusted $\mathrm{OR}=1.57,95 \% \mathrm{CI}:$ 1.34-1.85), high creatinine (adjusted OR=3.09, 95\% CI: 2.26-4.23), and high ALT levels (adjusted OR=1.36, 95\% CI: 1.14-1.64) after adjustment for sex and age.

The effects of independent associated risk factors on hyperuricemia were further examined using a multiple logistic regression model. After adjusting for confounding factors, age $(\mathrm{OR}=1.02,95 \% \mathrm{CI}:$ 1.01-1.03), obesity (yes versus no, $\mathrm{OR}=1.53,95 \% \mathrm{CI}$ : 1.32-1.77), type 2 diabetes (yes versus no, $\mathrm{OR}=1.16$, 95\% CI: 1.01-1.33), hypercholesterolemia 


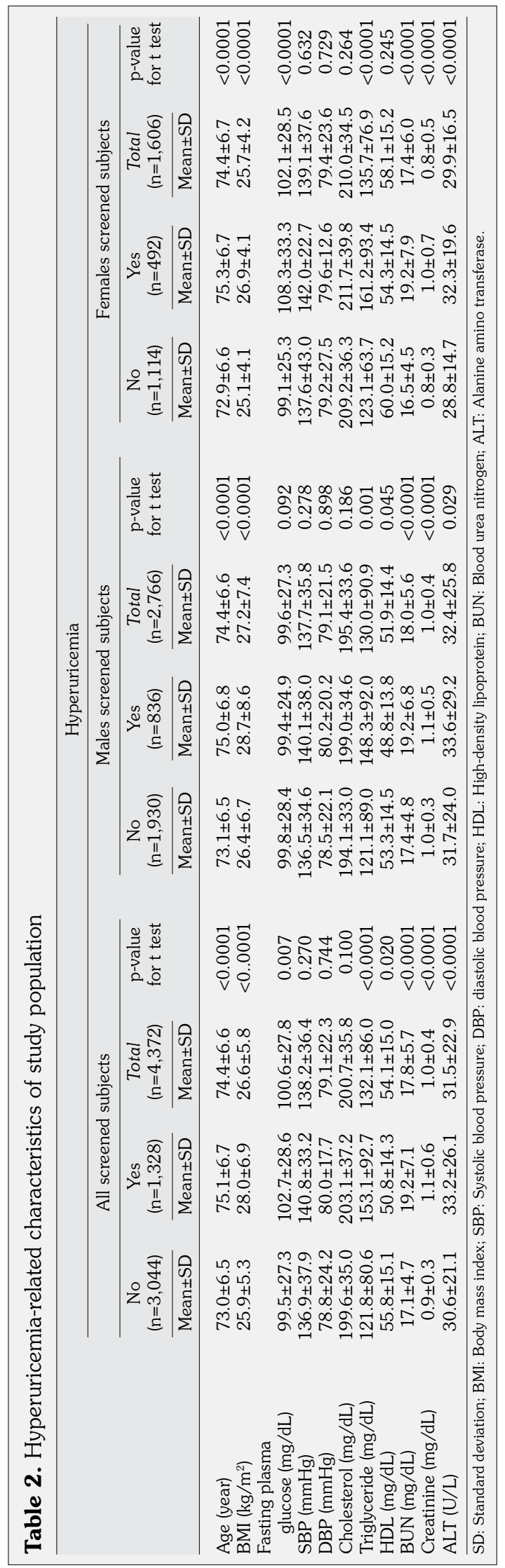

(yes versus no, OR=1.22, 95\% CI: 1.06-1.41), hypertriglyceridemia (yes versus no, $\mathrm{OR}=1.78$, 95\% CI: 1.52-2.09), low HDL (yes versus no, $\mathrm{OR}=1.54$, 95\% CI: 1.28-1.86), high BUN (yes versus no, $\mathrm{OR}=1.58,95 \% \mathrm{CI}$ : $1.34-1.85)$, high creatinine (yes versus no, $\mathrm{OR}=3.09,95 \% \mathrm{CI}$ : 2.26-4.23), and high ALT levels (yes versus no, $\mathrm{OR}=1.36,95 \% \mathrm{CI}$ : 1.14-1.64) appeared to be significantly associated with hyperuricemia (Table 4). Data in Table 4 also indicate the considerably different results of multiple logistic regression analysis stratified by sex. Among males, significant risk factors for hyperuricemia included age $(\mathrm{OR}=1.02,95 \% \mathrm{CI}$ : 1.01-1.04), obesity (yes versus no, $\mathrm{OR}=1.53,95 \% \mathrm{CI}$ : 1.28-1.84), hypercholesterolemia (yes versus no, $\mathrm{OR}=1.26$, 95\% CI: 1.05-2.50), hypertriglyceridemia (OR=1.70, 95\% CI: 1.38-2.08), low HDL (yes versus no, $\mathrm{OR}=1.52$, 95\% CI: $1.22-1.89$ ), high $\mathrm{BUN}$ (yes versus no, OR=1.35, 95\% CI: 1.10-1.65), and high creatinine levels (yes versus no, $\mathrm{OR}=3.75$, 95\% CI: 2.64-5.33). Among females, significant risk factors for hyperuricemia included age $(\mathrm{OR}=1.02,95 \% \mathrm{CI}$ : 1.00-1.04), obesity (yes versus no, OR=1.58, 95\% CI: 1.23-2.03), type 2 diabetes (yes versus no, OR=1.54, 95\% $\mathrm{CI}$ : 1.22-1.93), hypertriglyceridemia $(\mathrm{OR}=1.95$, 95\% CI: 1.52-2.51), low HDL (OR=1.65, 95\% CI: 1.14-2.39), high BUN (OR=2.22, 95\% CI: 1.69-2.92), and high ALT levels $(\mathrm{OR}=1.79$, 95\% CI: 1.31-2.43).

We next investigated whether age-related differences in hyperuricemia are associated with differences in the risk factors for hyperuricemia. Age-group disparities associated with hyperuricemia were also examined using the multiple logistic regression model. After adjustment for confounding factors, obesity and hypertension were the common factors associated with hyperuricemia (Table 5).

\section{DISCUSSION}

Hyperuricemia is considered to be the major etiological factor in gout. In addition to an inflammatory state triggered by urate crystal deposition in the joints, hyperuricemia has additional pathophysiological consequences causing tissue inflammation, mainly in the vascular wall. ${ }^{10}$ Epidemiological studies have also 
Table 3. Crude and adjusted odds ratios of hyperuricemia-related factors among study population

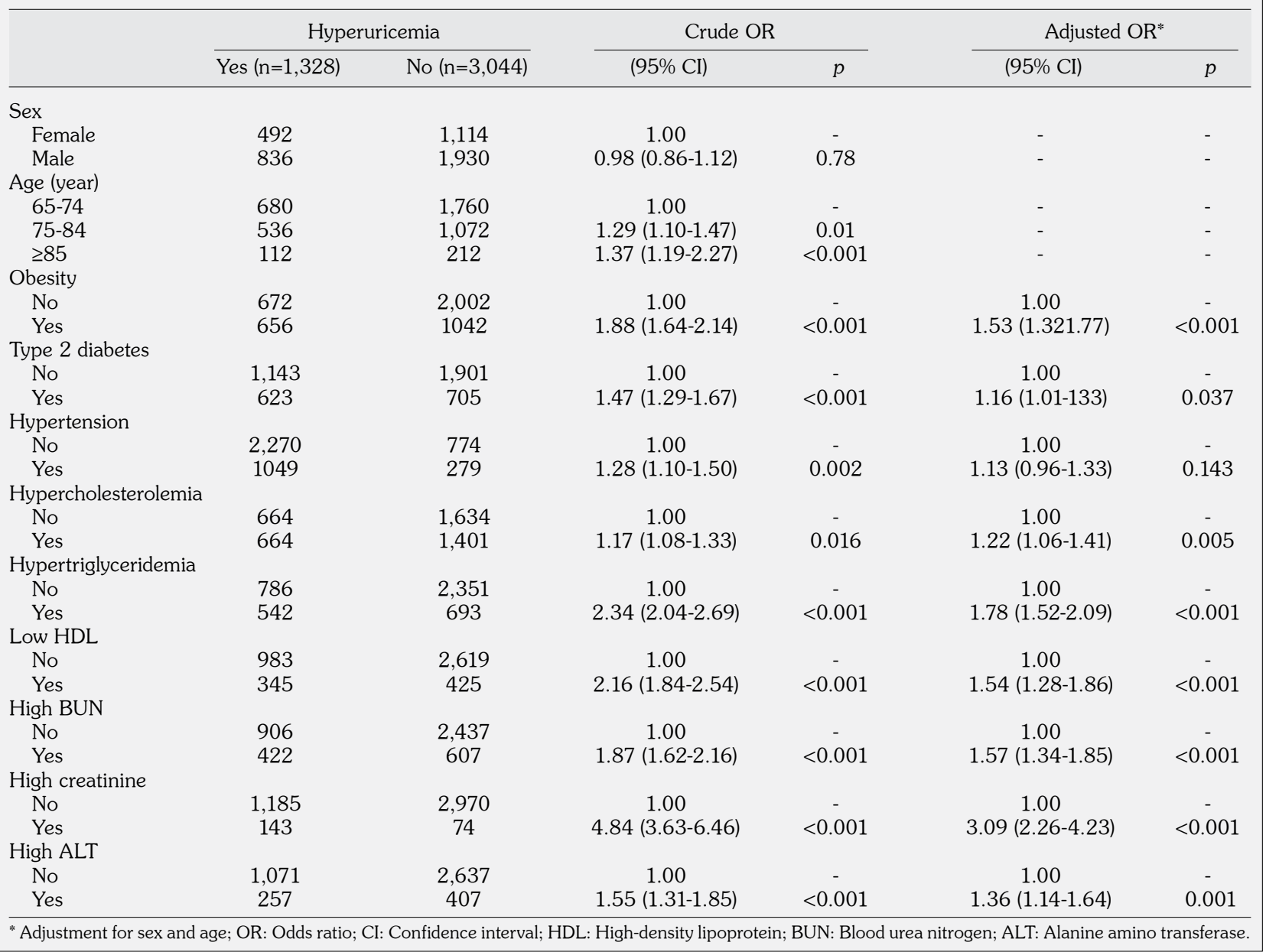

demonstrated that high serum uric acid levels are associated with type 2 diabetes, hypertension, stroke, atherosclerosis, cardiovascular disease, and metabolic syndrome; a large-scale investigation indicated that elevated serum uric acid levels are associated with an increased mortality rate..$^{1,11-14}$ Hyperuricemia appears to increase the risk of coronary heart disease events in the general population, mainly adult females. ${ }^{14}$

Social problems resulting from the division between rich and poor have led to the coexistence of unsustainable lifestyles among approximately one billion people in the developed world and unacceptable poverty in another one billion people, largely from developing countries. ${ }^{5}$ In this study, we used an age- and sex-based approach to estimate the morbidity of hyperuricemia in an elderly agricultural and fishing population. The prevalence of hyperuricemia in males and females was $30.2 \%$ and $30.6 \%$, respectively. In multiple logistic regression analysis, age, obesity, type 2 diabetes, hypercholesterolemia, hypertriglyceridemia, low HDL level, and high BUN, creatinine, and ALT levels were independent predictors of hyperuricemia. A crucial benefit of a uric acid screening program is that gout and other chronic complications are often detected in apparently healthy individuals through elevated serum uric acid levels because the related screening tests are commonly included in serum chemistry panels. ${ }^{5}$ The relative significance of these results is often overlooked when the serum uric acid levels are deemed slightly abnormal. In addition, the differences observed in factors associated with hyperuricemia in each age subgroup imply that multiple strategies for the health promotion of elderly people are necessary for reducing the risk of elevated serum uric acid levels. 
Table 4. Multiple logistic regression of hyperuricemia-related factors among study population

\begin{tabular}{|c|c|c|c|c|c|c|}
\hline & & & & $\begin{array}{l}\text { ruricemia } \\
\text { versus no) }\end{array}$ & & \\
\hline & & Male & & emale & & Total \\
\hline & OR & $95 \% \mathrm{CI}$ & OR & $95 \% \mathrm{CI}$ & OR & $95 \% \mathrm{CI}$ \\
\hline Age (year) & 1.02 & $1.01-1.04$ & 1.02 & $1.00-1.04$ & 1.02 & $1.01-1.03$ \\
\hline Sex (female versus male) & - & - & - & - & 0.83 & $0.72-1.27$ \\
\hline Obesity (yes versus no) & 1.53 & $1.28-1.84$ & 1.58 & $1.23-2.03$ & 1.53 & $1.32-1.77$ \\
\hline Type 2 diabetes (yes versus no) & 0.98 & $0.82-1.17$ & 1.54 & $1.22-1.93$ & 1.16 & $1.01-1.33$ \\
\hline Hypertension (yes versus no) & 1.09 & $0.89-1.34$ & 1.20 & $0.91-1.57$ & 1.13 & $0.96-1.33$ \\
\hline Hypercholesterolemia (yes versus no) & 1.26 & $1.05-2.50$ & 1.20 & $0.95-1.53$ & 1.22 & $1.06-1.41$ \\
\hline Hypertriglyceridemia (yes versus no) & 1.70 & $1.38-2.08$ & 1.95 & $1.52-2.51$ & 1.78 & $1.52-2.09$ \\
\hline Low HDL (yes versus no) & 1.52 & $1.22-1.89$ & 1.65 & $1.14-2.39$ & 1.54 & $1.28-1.86$ \\
\hline High BUN (yes versus no) & 1.35 & $1.10-1.65$ & 2.22 & $1.69-2.92$ & 1.58 & $1.34-1.85$ \\
\hline High creatinine (yes versus no) & 3.75 & $2.64-5.33$ & 1.68 & $0.82-3.40$ & 3.09 & $2.26-4.23$ \\
\hline High ALT (yes versus no) & 1.20 & $0.96-1.51$ & 1.79 & $1.31-2.43$ & 1.36 & $1.14-1.64$ \\
\hline
\end{tabular}

Agriculture includes both crop and animal husbandry and fisheries to produce the food requirements of humankind. ${ }^{15}$ Good health and appropriate training programs are essential for agricultural and fishing professionals. Their long or irregular working hours may cause adverse health effects. To the best of our knowledge, however, few clinical evidence-based studies have determined the prevalence and possible etiology of hyperuricemia among the elderly agricultural and fishing population in Taiwan. The prevalence of hyperuricemia in various populations are presented in Table 6. The prevalence of hyperuricemia among different screened populations seems to vary between countries. ${ }^{16-25}$ This disparity is likely due to differences among various populations with regard to participant characteristics (e.g., age, socioeconomic status, and abnormal associated factors), study period, and different diagnostic definitions for elevated serum uric acid levels. The prevalence of hyperuricemia in our study population (30.4\%) was higher than that reported in previous population-based studies conducted in general Chinese populations. ${ }^{11,16,20-22,25}$ The agricultural and fishing population endures strenuous working conditions, job stress, and reversed working and resting times compared to those of the general population. ${ }^{5}$ Irregular lifestyles and carelessness regarding personal health are also major problems in this population. These factors might partially explain the apparently high prevalence of hyperuricemia observed in our study. Another reason for the discrepancy between the results for the general population and our results may be the differences in the populations studied.

Table 5. Multiple logistic regression of hyperuricemia-related factors for stratified by age group

\begin{tabular}{|c|c|c|c|c|c|c|}
\hline & \multicolumn{2}{|c|}{$\begin{array}{c}\text { 65-74 years } \\
(\mathrm{n}=2,456)\end{array}$} & \multicolumn{2}{|c|}{$\begin{array}{c}\text { 75-84 years } \\
(\mathrm{n}=1,613)\end{array}$} & \multicolumn{2}{|c|}{$\begin{array}{c}\geq 85 \text { years } \\
(\mathrm{n}=326)\end{array}$} \\
\hline & OR & $95 \% \mathrm{CI}$ & OR & $95 \% \mathrm{CI}$ & OR & $95 \% \mathrm{CI}$ \\
\hline Sex (male versus female) & 0.80 & $0.65-0.98$ & 0.92 & $0.72-1.16$ & 0.61 & $0.35-1.07$ \\
\hline Obesity (yes versus no) & 1.57 & $1.29-1.92$ & 1.42 & $1.13-1.79$ & 1.83 & $1.03-3.24$ \\
\hline Type 2 diabetes (yes versus no) & 1.17 & $0.96-1.42$ & 1.20 & $0.96-1.50$ & 0.85 & $0.49-1.48$ \\
\hline Hypertension (yes versus no) & 1.24 & $0.99-1.55$ & 0.93 & $0.71-1.21$ & 1.52 & $0.79-2.95$ \\
\hline Hypercholesterolemia (yes versus no) & 1.04 & $0.85-1.26$ & 1.43 & $1.14-1.85$ & 1.91 & $1.10-3.30$ \\
\hline Hypertriglyceridemia (yes versus no) & 1.99 & $1.61-2.46$ & 1.58 & $1.21-2.05$ & 1.66 & $0.86-3.21$ \\
\hline Low HDL (yes versus no) & 1.36 & $1.05-1.76$ & 1.70 & $1.26-2.28$ & 2.41 & $1.20-4.83$ \\
\hline High BUN (yes versus no) & 1.47 & $1.16-1.86$ & 1.66 & $1.29-2.12$ & 1.93 & $1.11-3.33$ \\
\hline High creatinine (yes versus no) & 2.66 & $1.56-4.54$ & 2.83 & $1.83-4.38$ & 7.72 & $3.05-19.57$ \\
\hline High ALT (yes versus no) & 1.55 & $1.23-1.96$ & 1.18 & $0.86-1.61$ & 0.45 & $0.15-1.31$ \\
\hline
\end{tabular}


Table 6. Prevalence of hyperuricemia among various populations

\begin{tabular}{|c|c|c|c|c|c|}
\hline Author & Study year & Screened number & Setting & $\begin{array}{c}\text { Prevalence of } \\
\text { hyperuricemia (\%) }\end{array}$ & Associated factors \\
\hline Yu et al. ${ }^{16}$ & 2012 & 11,576 & Northeast China & $\begin{array}{c}\text { Overall: } 10.9 \\
\text { Male: } 15.0 \\
\text { Female: } 7.3\end{array}$ & $\begin{array}{c}\text { Abdominal obesity, general } \\
\text { obesity, hypertriglyceridemia, } \\
\text { hypertension, } \\
\text { hypercholesterolemia, low } \\
\text { HDL-C, ethnic minority, } \\
\text { physical activity, current } \\
\text { smoking, drinking }\end{array}$ \\
\hline Zhu et al. ${ }^{17}$ & 2007 & 5,707 & United States & $\begin{array}{l}\text { Overall: } 3.9 \\
\text { Male: } 5.9 \\
\text { Female: } 2.0\end{array}$ & Adiposity, hypertension \\
\hline You et al..$^{18}$ & 2009 & 1,426 & Mongolia & $\begin{array}{l}\text { Male: } 17.7 \\
\text { Female: } 5.2\end{array}$ & $\begin{array}{c}\text { Waist circumference, the level } \\
\text { of triglycerides }\end{array}$ \\
\hline Alikor et al. ${ }^{19}$ & 2013 & 500 & Nigeria & $\begin{array}{l}\text { Overall: } 17.2 \\
\text { Male: } 25 \\
\text { Female: } 13.7\end{array}$ & $\begin{array}{l}\text { Waist circumference, } \\
\text { total cholesterol, LDL, sex }\end{array}$ \\
\hline Qu et al. ${ }^{20}$ & 2007 & 9,354 & Three Gorges, China & $\begin{array}{l}\text { Male: } 5.6 \\
\text { Female: } 3.3\end{array}$ & $\begin{array}{l}\text { Alcohol drinking, low intake } \\
\text { of green vegetables and fruits }\end{array}$ \\
\hline Qiu et al. ${ }^{21}$ & 2008 & 13,141 & Northern China & $\begin{array}{l}\text { Overall: } 13.7 \\
\text { Male: } 21 \\
\text { Female: } 7.9\end{array}$ & $\begin{array}{c}\text { Age, sex, residence, obesity } \\
\text { hypertension, abdominal } \\
\text { obesity impaired fasting } \\
\text { glucose, CKD, drinking and } \\
\text { sleeping, } \\
\text { hypercholesterolemia, } \\
\text { hypertriglyceridemia, }\end{array}$ \\
\hline Yang et al. ${ }^{22}$ & 2012 & 4,218 & Jinan, China & $\begin{array}{c}\text { Male: } 6.4 \\
\text { Female: } 2.1 \\
\text { Urban: } 6.7 \% \\
\text { Rural areas: } 1.7 \%\end{array}$ & $\begin{array}{c}\text { Male sex, urban residence, } \\
\text { obesity, hypertension, high } \\
\text { serum creatinine level, hyper } \\
\text { triglyceridemia,hypercholeste } \\
\text { rolemia, }\end{array}$ \\
\hline Conen et al. ${ }^{23}$ & 2004 & 1,011 & $\begin{array}{l}\text { The Seychelles, Indian } \\
\text { Ocean, population } \\
\text { mainly of African origin }\end{array}$ & $\begin{array}{l}\text { Male: } 35.2 \\
\text { Female: } 8.7\end{array}$ & $\begin{array}{c}\text { Serum triglycerides, age, } \\
\text { BMI, blood pressure, alcohol, } \\
\text { the use of antihypertensive } \\
\text { therapy }\end{array}$ \\
\hline Nakamura et al. ${ }^{24}$ & 2011 & 3,310 & Japan & 21.6 & Habitual alcohol intake \\
\hline Lin et al. ${ }^{25}$ & 2010 & 2,145 & Taiwan & $\begin{array}{c}\text { Given thiazides: } 44 \% \\
\text { Given loop diuretics: } 56 \% \\
\text { Given aldosterone receptor } \\
\text { blockers: } 57 \%\end{array}$ & $\begin{array}{l}\text { Impaired renal function, } \\
\text { diuretic use }\end{array}$ \\
\hline
\end{tabular}

Older age was a significant risk factor for hyperuricemia even in our elderly study population. This finding is consistent with the results of previous hospital- and communitybased studies for general and occupational populations. ${ }^{11,21-23}$ The mechanism underlying the slightly lower prevalence of hyperuricemia in males aged $\geq 85$ than in those aged 75-84 years remains unclear; nevertheless, in females, the increase in hyperuricemia prevalence with increasing age may be explained by postmenopausal changes in the endocrine system and estrogen levels. ${ }^{22}$
Consistent with other studies, ${ }^{21,22,25}$ we observed a positive association between hyperuricemia and metabolic disorders in our Chinese population. Epidemiological studies have also reported an association between hyperuricemia and metabolic disorders such as metabolic syndrome, hyperlipidemia, obesity, and type 2 diabetes. ${ }^{11,22,25}$ Metabolic syndrome is a cluster of three diseases-hypertension, hyperglycemia, and gout, ${ }^{11}$ Although metabolic syndrome is clearly associated with obesity, insulin resistance, and abnormal blood lipids, which lead to the three diseases, the etiological mechanisms of this 
syndrome remain unknown. ${ }^{26}$ Previous studies have indicated that serum uric acid level can be used as a crucial predictor of metabolic syndrome and that the number of metabolic syndrome components increases the prevalence and OR for significantly increased uric acid activity. 11,27,28

Among patients with chronic hepatitis, fructose load may cause a substantial increase in serum uric acid levels. ${ }^{5,7}$ Furthermore, serum uric acid levels are high in patients with chronic liver lesions. Our results regarding the significant association between high serum ALT level and hyperuricemia are similar to those reported in other studies. ${ }^{5,29}$ However, because of the cross-sectional design of our study, we could not determine the extent to which the increase in serum ALT level occurs before hyperuricemia development.

Uric acid levels are high among renal failure patients because of decreased renal clearance. ${ }^{1}$ A decrease in the glomerular filtration rate contributes to hyperuricemia, frequently observed in patients with chronic kidney disease. ${ }^{30}$ Here, we observed a positive association between serum creatinine level and hyperuricemia, consistent with other studies. ${ }^{11,31}$ Although evidence-based studies have indicated that serum uric acid itself may harm patients with chronic kidney disease by increasing inflammation and progression, the topic remains controversial. ${ }^{31}$ In addition, we observed that BUN is strongly associated with hyperuricemia after adjustment for confounding factors. This suggests that BUN is an indicator of deterioration caused by hyperuricemia. A study indicated that despite significantly influencing serum uric acid, creatinine, and BUN levels, diuretic dose failed to emerge as the strongest predictor of serum uric acid in multiple regression analyses. This implied that increased diuretic dose may indirectly reflect the deterioration of renal function and clinical status. ${ }^{32}$

A major limitation of this study was potential selection bias because the screened elderly population was selected from only one area; this bias may have affected the estimated prevalence of and risk factors for hyperuricemia. Nevertheless, given our relatively large sample size, the statistical power was sufficient to effectively evaluate the presence of any sex differences between the various associated risk factors for hyperuricemia after adjusting for confounding factors. Second, we evaluated only elderly participants, who might have characteristics differing from those of the general population. This subpopulation is more susceptible to hyperuricemia than other populations in Taiwan. Third, some nonrespondents, who did not return for biochemical examination, may have had more prevalent hyperuricemia; thus, the prevalence may have been underestimated. Finally, our measurements were conducted at a single time point; hence, they cannot be used to reflect the effects of long-term exposure to the various risk factors, which may critically affect hyperuricemia. Thus, prospective longitudinal analogous studies are required, the results of which may complement the cross-sectional findings of this study.

In conclusion, in this study for prevalence of and risk factors for hyperuricemia in our elderly agricultural and fishing population, we noted several sex differences with regard to factors including age, obesity, type 2 diabetes, hypercholesterolemia, hypertriglyceridemia, low HDL level, and high BUN, creatinine, and ALT levels. Future studies are required to elucidate the temporal sequence of events typically leading to hyperuricemia and further explore the sex differences in the factors causing hyperuricemia among the elderly agricultural and fishing population.

\section{Declaration of conflicting interests}

The authors certify full disclosure of all affiliations or financial involvements with any organization or entity with a financial interest in or financial conflict with the subject matter or materials discussed in this manuscript, within the past five years and in the foreseeable future (e.g., employment, consultancies, honoraria, stock ownership or options, expert testimony, grants or patents received or pending, and royalties).

\section{Funding}

The authors received no financial support for the research and/or authorship of this article.

\section{REFERENCES}

1. Roozbeh J, Sagheb MM, Vafaie E. The association between blood pressure level and serum uric acid concentration in hemodialysis patients. J Nephropathol 2015;4:85-90. 
2. Smith EU, Díaz-Torné C, Perez-Ruiz F, March LM. Epidemiology of gout: an update. Best Pract Res Clin Rheumatol 2010;24:811-27.

3. Luk AJ, Simkin PA. Epidemiology of hyperuricemia and gout. Am J Manag Care 2005;11:435-42.

4. Campion EW, Glynn RJ, DeLabry LO. Asymptomatic hyperuricemia. Risks and consequences in the Normative Aging Study. Am J Med 1987;82:421-6.

5. Chen YF, Hu YC, Shen HC, Chang HT, Tung TH. Clinical implications in the prevalence and associated cardiovascular factors of elevated serum alanine aminotransferase levels among elderly agricultural and fishing population in Taipei, Taiwan: experience at a teaching hospital. J Investig Med 2014;62:88-96.

6. Tung T, Chiu W, Lin T, Shih H, Hsu C. An exploration of prevalence and associated factors of nonalcoholic Fatty liver disease in the taiwanese police service. Iran J Public Health 2011;40:54-62.

7. Liu CM, Tung TH, Chou P, Chen VT, Hsu CT, Chien WS, et al. Clinical correlation of gallstone disease in a Chinese population in Taiwan: experience at Cheng Hsin General Hospital. World J Gastroenterol 2006;12:1281-6.

8. World Health Organization. Definition, diagnosis and classification of diabetes mellitus and its complications: Report of a WHO Consultation. Part 1. Diagnosis and classification of diabetes mellitus. Geneva, World Health Organization, 1999

9. Cuddy ML. Treatment of hypertension: guidelines from JNC 7 (the seventh report of the Joint National Committee on Prevention, Detection, Evaluation, and Treatment of High Blood Pressure 1). J Pract Nurs 2005;55:17-21.

10. Gliozzi M, Malara N, Muscoli S, Mollace V. The treatment of hyperuricemia. Int J Cardiol 20165;213:23-7.

11. Wei CY, Sun CC, Wei JC, Tai HC, Sun CA, Chung CF, et al. Association between Hyperuricemia and Metabolic Syndrome: An Epidemiological Study of a Labor Force Population in Taiwan. Biomed Res Int 2015;2015:369179.

12. Guo M, Niu JY, Li SR, Ye XW, Fang H, Zhao YP, et al. Gender differences in the association between hyperuricemia and diabetic kidney disease in community elderly patients. J Diabetes Complications 2015;29:1042-9.

13. Wang $H$, Jacobs DR Jr, Gaffo AL, Gross MD, Goff DC Jr, Carr JJ. Serum Urate and Incident Cardiovascular Disease: The Coronary Artery Risk Development in Young Adults (CARDIA) Study. PLoS One 2015;10:0138067.

14. Braga F, Pasqualetti S, Ferraro S, Panteghini M. Hyperuricemia as risk factor for coronary heart disease incidence and mortality in the general population: a systematic review and meta-analysis. Clin Chem Lab Med 2016;54:7-15.

15. Kesavan PC, Swaminathan MS. Strategies and models for agricultural sustainability in developing Asian countries. Philos Trans R Soc Lond B Biol Sci 2008;363:877-91.

16. Yu S, Yang H, Guo X, Zhang X, Zhou Y, Ou Q, et al. Prevalence of hyperuricemia and its correlates in rural Northeast Chinese population: from lifestyle risk factors to metabolic comorbidities. Clin Rheumatol 2016;35:1207-15.
17. Zhu Y, Pandya BJ, Choi HK. Prevalence of gout and hyperuricemia in the US general population: the National Health and Nutrition Examination Survey 2007-2008. Arthritis Rheum 2011;63:3136-41.

18. You L, Liu A, Wuyun G, Wu H, Wang P. Prevalence of hyperuricemia and the relationship between serum uric acid and metabolic syndrome in the Asian Mongolian area. J Atheroscler Thromb 2014;21:355-65.

19. Alikor CA, Emem-Chioma PC, Odia OJ. Prevalence of hyperuricaemia in a rural population of Nigerian Niger Delta region. Niger J Med 2013;22:187-92.

20. Qu YL, Yu L, Li ZM, Kong LH, Xiao TC, Li M, et al. Epidemiological status and risk factors of hyperuricemia in rural area of the Three Gorges. Zhonghua Xin Xue Guan Bing Za Zhi 2013;41:427-31.

21. Qiu L, Cheng XQ, Wu J, Liu JT, Xu T, Ding HT, et al. Prevalence of hyperuricemia and its related risk factors in healthy adults from Northern and Northeastern Chinese provinces. BMC Public Health 2013;13:664. doi: 10.1186/1471-2458-13-664.

22. Yang J, Liu Z, Zhang C, Zhao Y, Sun S, Wang S, et al. The prevalence of hyperuricemia and its correlates in an inland Chinese adult population, urban and rural of Jinan. Rheumatol Int 2013;33:1511-7.

23. Conen D, Wietlisbach V, Bovet P, Shamlaye C, Riesen W, Paccaud F, et al. Prevalence of hyperuricemia and relation of serum uric acid with cardiovascular risk factors in a developing country.BMC Public Health 2004;4:9.

24. Nakamura K, Sakurai M, Miura K, Morikawa Y, Yoshita K, Ishizaki M, et al. Alcohol intake and the risk of hyperuricaemia: a 6-year prospective study in Japanese men. Nutr Metab Cardiovasc Dis 2012;22:989-96.

25. Lin CS, Lee WL, Hung YJ, Lee DY, Chen KF, Chi WC, et al. Prevalence of hyperuricemia and its association with antihypertensive treatment in hypertensive patients in Taiwan. Int $\mathrm{J}$ Cardiol 2012;156:41-6.

26. Yang YC, Chang CJ. Metabolic syndrome, obesity and diabetes. Formosan J of Med 2007;2:370-80.

27. Corry DB, Eslami P, Yamamoto K, Nyby MD, Makino H, Tuck ML. Uric acid stimulates vascular smooth muscle cell proliferation and oxidative stress via the vascular renin-angiotensin system. J Hypertens 2008;26:269-75.

28. Facchini F, Chen YD, Hollenbeck CB, Reaven GM. Relationship between resistance to insulin-mediated glucose uptake, urinary uric acid clearance, and plasma uric acid concentration. JAMA 1991;266:3008-11.

29. Bruckert E, Giral P, Ratziu V, Poynard T, Chapman MJ, Opolon $\mathrm{P}$, et al. A constellation of cardiovascular risk factors is associated with hepatic enzyme elevation in hyperlipidemic patients. Metabolism 2002;51:1071-6.

30. Prasad Sah OS, Qing YX. Associations between hyperuricemia and chronic kidney disease: a review. Nephrourol Mon 2015;7:27233.

31. Nakamura K, Sakurai M, Miura K, Morikawa Y, Yoshita K, Ishizaki M, et al. Alcohol intake and the risk of hyperuricaemia: a 6-year prospective study in Japanese men. Nutr Metab Cardiovasc Dis 2012;22:989-96.

32. Tian Y, Chen Y, Deng B, Liu G, Ji ZG, Zhao QZ, et al. Serum uric acid as an index of impaired renal function in congestive heart failure. J Geriatr Cardiol 2012;9:137-42. 